\title{
The Trials and Tribulations of an Indian Ace Shooter: The Road to Gold
}

\author{
Abhinav Bindra ${ }^{1}$ \\ Published online: 8 April 2020 \\ (c) Indian Orthopaedics Association 2020
}

\begin{abstract}
Athletes that excel in their field, and are hence declared "elite", have many challenges and problems in their career. The path to glory is often littered with personal sacrifice, rigorous schedules and many related medical issues from orthopaedic injuries specific to individual sports, to mental health issues that are often not diagnosed. Coupled with that, the lack of support to these sportspersons in underdeveloped countries, makes their road to the top much more challenging. Commitment of time, continuance of effort and perseverance are key components. The current account of a difficult journey and the issues that were overcome serves as a guide to aspiring athletes and to support staff ranging from doctors to physiotherapists and perhaps even the sports administrators.
\end{abstract}

Keywords Elite athlete $\cdot$ Olympics $\cdot$ Shooting $\cdot$ Sports $\cdot$ Perseverance

The journey of an athlete who excels in his field is a fine line to tread and is fraught with multiple challenges that he has to overcome. I was asked by the editors of the Indian Journal of Orthopaedics to outline some of my personal tribulations, medical and non-medical, as part of a special issue on sports medicine, and I readily agreed, since I have faced many obstacles and I hope this article may help guide those who follow my path.

I started shooting at the age of 13 , which is a young age for shooters. Lt. Colonel Dhillon was my first coach, who taught me how to shoot, and thus began my fascination for shooting as a sport. My interest in shooting was reinforced by watching the 1992 Barcelona Games, where I watched Limba Ram shoot. I was very fascinated and drawn by the spectacle and the magnitude of the event, and somewhere during that phase, began my obsession of winning a Gold at the Olympics.

I have spent considerable time in my career looking at the most scientific and minute details of training, as I truly believe that it is the little things that make a difference between being great, and excellent.

In the early phases of my career, I was not an athlete by any stretch of imagination. I was, however, diligent, and persevering; I spent hours perfecting my skills, and training

Abhinav Bindra

office@abhinavbindra.com

1 Mohali, India all about the "process". It was something I loved; day-inand-day-out of training. As a kid, I used to buy aircraft and car models and painstakingly construct them with my father helping me out, one tiny part after another, never skipping a detail. This helped me in shooting, as this is an essential component in the gradual, systematic accumulation of knowledge, along with the ability to repeat and focus on the smallest of details. In my mind it was an interest, a quirk even, while all the other kids were out playing. It was only much later, when I started working with my professional coaches Gaby, Heinz and Uwe did the penny drop. These relationships taught me that there is a passion that is right for every one of us to find. Mine was sport shooting and I felt that it belonged to me and I belonged to it (Fig. 1).

Shooting as a sport is a very high maintenance endeavour. I was extremely fortunate to have a family that backed me financially and made sure that I waited for nothing. However, the challenges in India at that time were lack of expertise and mentorship, lack of training facilities, and the need to go through the (at the time) unorganised structure of Indian shooting; this required commitment and perseverance, if I was to progress towards my goals. My coaches remain the people I ask about any important decision even today-from the big decisions to the littlest of things in my life. These were relationships that transformed me and gave me faith in myself and a sense of belonging and identity. They did not give me answers, they gave me the tools to find my own. Thanks to my family that I had learnt to trust. 


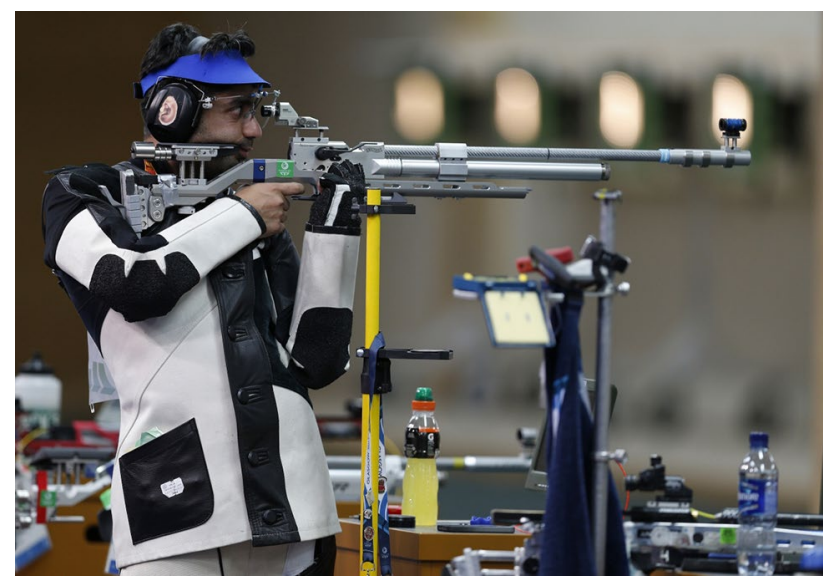

Fig. 1 The shooting gear

I have been very privileged to have a strong support team of physiotherapists who have been a strong influence in my training and showed an equal interest in the use of technology and timely interventions to ensure "Physical Self Awareness". It is essential for athletes to have physiotherapists who work with coaches to understand the technical standpoints of training and customize routines. This is a major factor hindering elite athletes in India, but I was fortunate to have had such individuals work with me. All of my training was data-driven and allowed me to understand exactly what I needed to do to improve my game.

In addition to developing the body, modern sports science has understood the significance of the mind as a key component in the formation of an "Elite Athlete." A great example is my work with Tim Harkness, now the Head of Sports Sciences at Chelsea F.C. He helped me train my mind when practising, giving me insights on the part of my brain that needs to be active when I shoot a good shot. For example, when you are shooting, your occipital cortex (the part of the brain that sees) needs to be active. However, your Broca's area (the part of the brain that talks) needs to be quite inactive! The last thing you want when shooting under pressure is a voice that keeps saying, "Don't Miss!". The "Mind Mapping Process" is something that helped me considerably when I was in the competition phases, and this issue was little understood in India at that time.

When I was training in Germany, Tim rigged up a "distraction machine". He had a pulley system that would pull trolleys backward and forward, just inside my field of vision. Rattles would bang, just as I was about to pull the trigger. When announcing my scores, Tim would "cheat", and give me a lower score than I had actually shot, or give me less time to shoot than I was really allowed. He would lean into my face with a camera, and take photographs of me using flashes, while I was aiming. These were regularly incorporated into my day to day training. However, these distracting training exercises helped me focus better, and over time, the more the distractions, the more I focused.

Writing for an orthopaedic journal means detailing the injuries suffered on the road to glory. Nothing is more disheartening than an injury to an athlete; the physical, mental, and emotional strain on getting back to fitness is exhausting. The ideal posture for a shooter is by no stretch of the imagination good for the back. In my case too, this began to cause excruciating pain in the lead up to the 2006 Commonwealth Games. Since I was not naturally flexible enough to remain in my shooting position comfortably, the right side of my back would be strained unnecessarily, leading to bulging of the discs in my back. I remember many doctors in India had suggested even surgery, but I remained apprehensive, once the pros and cons were discussed.

After a lot of advice, and much introspection, I chose to begin rehabilitation in Germany with Dr. Jochaim Schubert, a doctor who recommended strengthening the weak muscles and improving my flexibility. This method was appealing to me as it targeted of the root of my problem, rather than just alleviating pain, or something as complicated as a surgery. It made quite a difference over time, and since then, I have seen more and more work being done on the forms of rehabilitation that can help a patient avoid surgery, which is an option that does put more patients at ease.

Coming to the Beijing Olympics, my preparation began on the back of a disappointing 2004 Athens Olympics. I got a disappointing 7th position in the 2004 Olympic finals in Athens, after what I thought was the perfect shooting game. Looking back, I don't think I shot better at any Olympic Games. Only much later did I find out that the lane position I was allotted had a loose tile underfoot, which reverberated every time I shot. In a game of millimetres, it was amazing that I even hit the target! I literally went into a depression after Athens.

One day, I received an unexpected letter from my coach Uwe. The letter included the following advice:

"I just want to tell you:

You are next in line!

World Champion in 2006

Olympic Champion in 2008.

Be focused but not intolerant.

Be flexible (and reassess!), don't be stubborn and self-centred

Know what you want and make sure you get what you want. Be a pro!

At the end: it is only a game but it is also the best school of life!

Never look back, always ahead."

Dealing with the disappointment of Athens defined the rest of my shooting career. Receiving this letter was a turning point of sorts because it reminded me why I was in this sport, what I dreamt of and what it meant to me 
to follow this passion. How did I build on it? I had two obvious choices-one, quit the sport or, two, carry on and accept the incident as 'bad luck'. I chose a third option and it defined me. I chose to try to be perfect on the imperfect day. I started training under deliberately imperfect conditions, even installing a loose tile in my home range and practicing regularly while standing on it. I trained under low light and bright lights, adjusted bulbs and added peculiar shadows, painted the walls the same colours as the relevant Olympic ranges. Extreme behaviour perhaps. But it worked for me.

And finally, in 2008, I won the gold in Beijing (Fig. 2). While this was clearly a great result and very meaningful in the context of Indian sport, at a personal level, I was not at all interested in the result. The process was everything to me. I did not rejoice in the ways that one might have expected. I did not even feel particularly special; I can honestly say I have shot better on other days. I do not attempt to belittle my own achievement or posture false modesty; I simply relate this because I think it might be valuable for the public to know.

However, this is still the first part; the road to get back to your best still lies ahead. We come to Rio in 2016; I was a former gold medallist and Olympic champion by this time, and the pressure is different. A few months before the Olympics I start feeling tremors in my hands and body. This is like a death sentence to a shooter; I find out that I have a form of epilepsy, and the next few months were the toughest phase of my life. However, I had to adapt my game, my training routines, and simultaneously give myself a reason to persevere. I can attest a lot of my balance and physical wellness to the machines that I was privileged to use and integrate into my Olympic Training Programme. Machines like the ProKin,

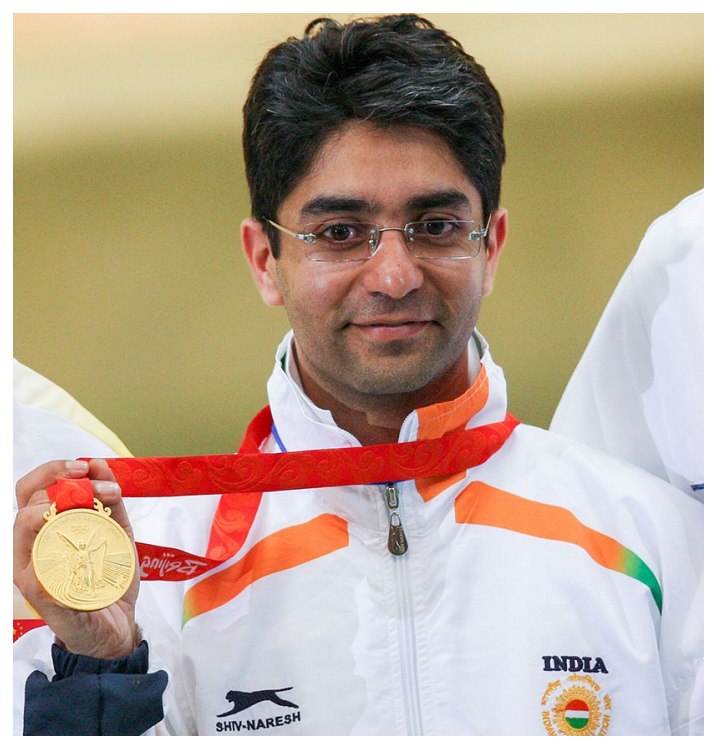

Fig. 2 Winning the Olympic Gold Medal which I have brought to India through my company, helped a great deal in ensuring my static and my dynamic stability became better over time. Through working out in the gym, and through yoga, which became extremely important to me during the last few years of my career, I trained hard to ensure that I remained competing to the highest level.

I represented India at five Olympic Games, from Sydney to Rio. I shot my very best at Athens 2004 where I finished 7th and I enjoyed Rio 2016 the most, where I finished 4th. In between I won an Olympic gold medal in 2008. It was not that I did not shoot well at Beijing or that I did not enjoy the Games but looking back at the journeys, one is reminded that the external validation of achievement does not always fully align with what goes on within us, or what motivates and moves us. Perhaps that is what I learnt in hindsight; that the wins don't necessarily mean the best possible result.

After winning Olympic gold, I was still a seeker and it took me two more Olympics to hang up my boots, before I knew I had given it my all. London in 2012 and Rio in 2016 closed a loop and gave me what I was seeking the most-not another medal but self-respect and closure. Once again it was my sport that gave me a lens to know myself, my body, my mind, my emotions. To make them work for me and to know what I wanted of myself.

I left the sport when I knew I had nothing more to give; I finally had my self-respect. Ultimately, that was the largest prize of all. Greater satisfaction than any gold medal could give. Honestly, the only thing that gives me nightmares today is to think of what kind of person I might have been had I not been a professional shooter!

Today, I am excited about what the future holds; I work with my foundation, the Abhinav Bindra Foundation, to provide scholarships to other young sportspeople who dream about Olympic success and need those little bits of support that can make the difference. It is still a part of my journey because once you have received, the acts of giving and passing on take on so much more meaning. I hope that I can make a difference to others in the way my support group did for me.

A lot of the work that I do revolves around a pursuit of excellence. After 22 years and nearly 150 medals in total, I am confident that the most important quality that an athlete can possess is integrity. I believe it is paramount that everyone, be it an athlete, a physician, or someone with a 9-5 job needs to be honest about their work, and be accountable for the time that they put in, as well as the commitment that they show in their journey. I reiterate that while I may not be an extremely gifted athlete, I was someone that was honest with myself about what I needed to achieve, the right way to go about it, and the need to persevere to attain my goal.

A story that I am very proud of, and still recount as a testament to my success, is the day I was working on strength and conditioning. My coach had asked me to do a hundred 
push-ups; I was a few short of the 100 mark, at which point, my coach told me to wrap up. Perhaps he miscounted. Most would let it slide and go away, happy not having to put in the effort. However, I corrected him and went on to complete all the hundred push-ups before I wrapped up training for the day.

The road to excellence is a fine line to tread and is fraught with challenges to overcome. But having completed my athletic journey to the pinnacle of success, I can proclaim that with integrity, perseverance, and a strong support system, anything is possible to achieve!

\section{Compliance with Ethical Standards}

Conflict of interest The authors declare that they have no conflict of interest.
Ethical standard statement This article does not contain any studies with human or animal subjects performed by the any of the authors.

Informed consent For this type of study informed consent is not required.

Publisher's Note Springer Nature remains neutral with regard to jurisdictional claims in published maps and institutional affiliations. 